\title{
Analisis Kesalahan Berbahasa Tataran Morfologi Pada Berita Daring Timlo.net
}

\author{
BHIAN CAHYA W.R \\ Universitas Sebelas Maret, Surakarta \\ bhianjavanica@gmail.com
}

\begin{abstract}
This research describes morphological level language errors in Timlo.net online news. This research method is Descriptive Analysis. The results of the study showed language errors in the level of morphology in the online news Timlo.net include: affixation, abbreviations, use of foreign words, use of standard words, use of the word join, and reduplication. From the results of this study it can be concluded that online news in the future should not be just any news publishing. Online news media must be careful in correcting the writing of the language again by prioritizing Indonesian rules. The media must be a role model and a pioneer in the use of Indonesian language that is good and right.
\end{abstract}

KEYWORDS

Language errors, morphology, online news

\begin{abstract}
ABSTRAK
Penelitian ini mendeskripsikan kesalahan berbahasa tataran morfologi pada berita daring Timlo.net. Metode penelitian ini adalah Deskriptif Analisis. Hasil penelitian menunjukkan kesalahan berbahasa tataran morfologi pada berita daring Timlo.net meliputi : afiksasi, singkatan, penggunaan kata asing, penggunaan kata baku, penggunaan kata gabung, dan reduplikasi. Dari hasil penelitian ini dapat disimpulkan bahwa berita daring kedepannya tidak boleh sembarang mempublikasikan berita. Media berita daring harus jeli mengoreksi penulisan bahasanya kembali dengan mengutamakan kaidah bahasa Indonesia. Media harus menjadi teladan dan pelopor dalam penggunaan bahasa Indonesia yang baik dan benar.
\end{abstract}

KATA KUNCI

Kesalahan berbahasa, morfologi, berita daring

\section{PENDAHULUAN}

Setiap orang memiliki kemampuan berpikir dengan baik, namun tidak semua orang memiliki kemampuan berbahasa dengan baik. Bahasa dan berbahasa mampu mendefinisikan pola jati diri, pola karakter, dan pola berpikir seseorang. Belajar bahasa secara tidak langsung akan belajar tentang budaya (Rondiyah dkk, 2017). Bahasa dan budaya memang tidak bisa dipisahkan. Bahasa memang sangat penting di masyarakat, "language is one of culture elements which also as a tool to express culture values of the society speakers" (Saddhono, 2015). Menggunakan bahasa harus sesuai dengan kaidah yang baik dan benar. Hal ini tentunya akan berpengaruh saat kita berkomunikasi. Bahasa juga dapat dikatakan sangat penting, Bahasa yang digunakan itu hendaklah dapat mendukung maksud secara jelas agar apa yang dipikirkan, diinginkan, atau dirasakan itu dapat diterima oleh pendengar 
atau pembaca (Widwiarti, 2014). Salah satu dalam keterampilan berbahasa adalah kemampuan menulis. Keterampilan menulis merupakan kemampuan yang cukup penting. Kemampuan menulis artinya mengungkapkan sebuah pikiran, gagasan, pendapat, dan perasaan yang dimiliki melalui bahasa tulis. Dalam menulis semua unsur keterampilan berbahasa harus dikonsentrasikan secara penuh agar mendapat hasil yang benar-benar baik (Sardila, 2016).

Kemampuan menulis tentunya tidak terlepas dari pemakaian bahasa. Semuanya harus dikaji dengan benar dan diteliti. Dalam mengkaji pemakaian bahasa tersebut, tentu perlu dikemukakan pula hal-hal yang terkait lainnya yang mempengaruhi hasil akhir dari kajian tersebut. Hal-hal terkait yang dimaksud misalnya adalah tentang sikap bahasa masyarakat tersebut, kemampuan dan pemakaian bahasanya dalam kehidupan sehari-hari, di samping situasi kebahasaan secara umum dalam masyarakat tersebut perlu pula diungkapkan (Saddhono, 2006). Terkhusus kita sebagai mahasiswa, penggunaan bahasa sangatlah penting. Dengan menguasai bahasa Indonesia, mereka akan lebih mudah untuk berkomunikasi baik komunikasi secara lisan maupun tulis, terutama untuk dalam proses pembelajaran dan menyelesaikan tugas akademik di kampus (Saddhono, 2012).

Menulis bukan hanya menceritakan pribadi penulis namun dalam tulisan tersebut juga dapat dituliskan peristiwa-peristiwa yang terjadi di sekitar. Menulis juga sebagai proses penemuan yang membutuhkan proses perjalanan panjang dan bertahap untuk menghasilkan tulisan finalnya (Astuti\&Mustadi, 2014). Keterampilan menulis sangatlah penting untuk dikuasai. Salah satu cara untuk mengungkapkan gagasan kita yaitu melalui media daring. Media daring adalah media yang dipublikasikan di internet dan merupakan produk jurnalistik daring. Beberapa masyarakat lebih menyukai sumber informasi dari surat kabar karena dianggap validitasnya lebih tinggi dibandingkan dengan situs berita daring yang kerap kali memberitakan berita palsu untuk menipu dan mengakali pembaca atau lebih kita kenal dengan istilah hoax (Sutrisna, 2017) Namun dalam kaitannya mengenai penggunaan bahasa indonesia yang baik dan benar, masih banyak media yang dalam menuliskan beritanya terdapat kesalahan-kesalahan berbahasa. Pada kegiatan bertutur, timbulnya kesalahan berbahasa dapat disebabkan oleh adanya hambatan dalam berkomunikasi (Fatimah dkk, 2018) Mungkin saja hal itu dikarenakan dalam penulisan berita di media internet dilakukan tergesa-gesa apalagi jika wartawan yang menulisnya kurang atau tidak menguasai tata bahasa dengan baik dan benar. Kesalahan berbahasa adalah penggunaan bahasa yang menyimpang dari kaidah bahasa yang berlaku dalam suatu bahasa (Nurwicaksono\&Diah, 2018). Kesalahan berbahasa dalam bahasa Indonesia dikelompokkan menjadi kesalahan berbahasa dalam bidang fonologi, morfologi, sintaksis, semnatik, dan diksi. Dalam penelitian ini bertujuan untuk mendeskripsikan analisis kesalahan berbahasa tataran morfologi pada berita daring Timlo.net.

Morfologi merupakan cabang dari linguistik yang mengidentifikasi mengenai satuan-satuan dasar bahasa sebagai satuan gramatikal. Dalam arti luas morfologi merupakan satu sistem dari suatu bahasa, sehingga struktur kata yang senantiasa membentuk kalimat-kalimat tentu mengalami perubahan-perubahan sesuai dengan jenis kata atau makna yang dikehendaki oleh penutur atau penulisnya (Priyono, 2012). Dalam kaitannya dengan kebahasaan, yang dipelajari dalam morfologi ialah bentuk kata. Sebagian besar kajian morfologi dilakukan dengan teori morfologi struktural yang mengangkat fenomena bahasa yang diteliti dengan tidak memuaskan (Ambarita\&Sibarani, 2017). Afiks ada empat macam yaitu prefiks yang diimbuhkan di sebelah kiri dasar dalam proses yang disebut "prefiksasi" (Inderasari\&Agustina, 2017). Morfologi sangat erat kaitannya dengan morfem. Dengan demikian morfem dapat dikatakan sebagaisatuan bahasa terkecil yang memiliki arti (Ariyani, 2014).

Sejalan dengan hal itu, (Utami, 2017) menjelaskan mengenai analisis kesalahan berbahasa, yaitu analisis kesalahan berbahasa pada tataran morfologi terbagi atas kesalahan afiksasi, reduplikasi, dan kesalahan pemajemukan. Adanya analisis kesalahan berbahasa 
yang diteliti dengan tataran morfologi pada salah satu berita daring ini tentunya dapat dijadikan bahan evaluasi agar kedepannya berita-berita hadir dengan pembaharuan yang lebih baik, mulai dari segi bahasa maupun konten isinya. Pemakaian bahasa yang bersifat merusak atau menyimpang dari kaidah seharusnya dihindari pemakaiannya (Saddhono, 2007). Penggunaan bahasa yang baik dan benar sangatlah penting. Bahasa jangan sampai rancu, Perilaku berbahasa Indonesia yang didasari kebiasaan tanpa pertimbangan baikburuk dan benar-salahnya akan berakibat kerancuan dalam berbahasa (Marsudi\&Zahrok, 2015).

\section{METODE PENELITIAN}

Metode penelitian yang digunakan dalam penelitian ini menggunakan metode deskriptif analisisis. Metode deskriptif analisis sangat cocok karena metode ini untuk meneliti gagasan atau produk pemikiran dari manusia yang telah tertuang dalam bentuk media cetak, baik yang berbentuk naskah primer maupun naskah sekunder dengan melakukan studi kritis terhadapnya (Nurwicaksosno\&Diah, 2018). Pelaksanaan metode penelitian yang digunakan tentunya tidak terbatas pada pengumpulan dan penyusunan data, tetapi juga analisis lengkap dan interpretasi tentang data tersebut. Sumber data dalam penelitian ini adalah berita daring Timlo.net.

\section{HASIL DAN PEMBAHASAN \\ Deskripsi data}

Peneliti membaca berita daring Timlo.net. Peneliti mengamati kesalahan berbahasa tataran morfologi yang terdapat dalam berita daring Timlo.net untuk mendapatkan data. Hasil data yang telah diperoleh, dianalisis dan diklasifikasi menurut kesalahan morfologi yang terjadi.

Tabel 1. Deskripsi Analisis Data Kesalahan Morfologi Berita Online Timlo.net

\begin{tabular}{|c|c|c|c|}
\hline No & Judul Berita & URL Berita & Kesalahan Morfologi \\
\hline 1 & $\begin{array}{l}\text { Pegawai Setda } \\
\text { Gelar } \\
\text { Gathering, } \\
\text { Bupati: Untuk } \\
\text { Melepas Penat }\end{array}$ & $\begin{array}{l}\text { https://timlo.net/baca/59551/p } \\
\text { egawai-setda-gelar-gathering- } \\
\text { bupati-untuk-melepas-penat/ }\end{array}$ & 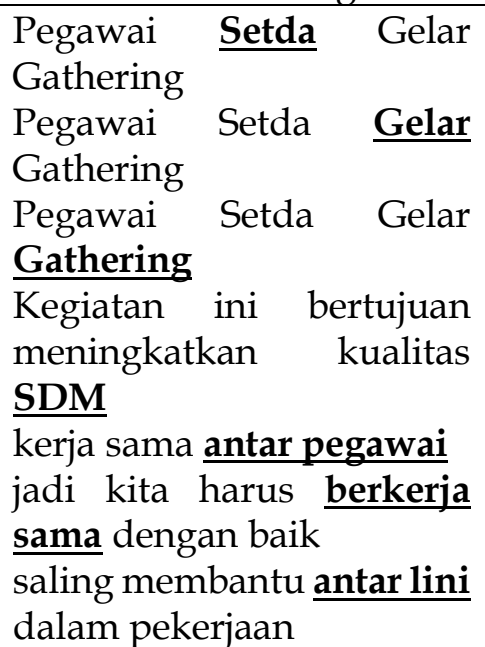 \\
\hline 2 & $\begin{array}{lr}\text { Tak Ada } & \text { Hujan } \\
\text { Tak Ada } & \text { Angin, } \\
\text { Suzuki } & \text { Ignis } \\
\text { Nyungsep } & \text { ke } \\
\text { Selokan } & \end{array}$ & $\begin{array}{l}\text { http://timlo.net/baca/64681/ta } \\
\text { k-ada-hujan-tak-ada-angin- } \\
\text { suzuki-ignis-nyungsep-ke- } \\
\text { selokan/ }\end{array}$ & $\begin{array}{l}\text { Tak Ada Hujan Tak Ada } \\
\text { Angin, Suzuki } \\
\text { Nyungsep keSelokan } \\
\text { Tak Ada Hujan Tak Ada } \\
\text { Angin, Suzuki Ignis } \\
\text { Nyungsep ke Selokan } \\
\text { Tak ada korban jiwa, } \\
\text { hanya hanya luka ringan }\end{array}$ \\
\hline
\end{tabular}




\begin{tabular}{|l|l|l|l|}
\hline & & $\begin{array}{l}\text { Seluruh korban langsung } \\
\text { dievakuasi ke RS } \\
\text { Bhayangkara Polda Jatim }\end{array}$ \\
\hline & & & \\
\hline
\end{tabular}

Tabel 2. Klasifikasi Data Kesalahan Morfologi Berita Daring Timlo.net

\begin{tabular}{|l|l|l|l|}
\hline No. & $\begin{array}{l}\text { Kesalahan } \\
\text { Morfologi dalam berita }\end{array}$ & Salah & Benar \\
\hline 1. & Afiksasi & & \\
\hline & be(R)- & berkerja sama & bekerja sama \\
\hline & me (N) & gelar & menggelar \\
\hline 2. & singkatan & Setda & Sekretaris Daerah \\
\hline & & Polda Jatim & $\begin{array}{l}\text { Polisi Daerah Jawa } \\
\text { Timur }\end{array}$ \\
\hline & & SDM & Sumber Daya Manusia \\
\hline 3. & Kata asing & Gathering & Gathering \\
\hline & & Suzuki Ignis & Suzuki Ignis \\
\hline & & & Masuk atau terjun \\
\hline 4. & Kata baku & Nyungsep & \\
\hline & & & antarpegawai \\
\hline 5. & Kata gabung & Antar pegawai & antarlini \\
\hline & & Antar lini & \\
\hline & & & hanya \\
\hline 6. & Reduplikasi & hanya hanya & \\
\hline
\end{tabular}

\section{Hasil Analisis Data}

Berdasarkan deskripsi dan klasifikasi data di atas telah disebutkan ada beberapa kesalahan berbahasa khususnya pada bidang morfologi. Pada tataran morfologi Kesalahan Berita Daring Timlo.net dapat dikategorikan berdasarkan kategori: 1) afiksasi, 2) singkatan, 3) kata asing 4) kata baku, 5) kata antar 6) reduplikasi.

Berikut ini merupakan uraian hasil analisis data Kesalahan bidang morfologi pada Berita Daring Timlo.net :

Pertama, Kesalahan Afiksasi ditemukan dalam Berita Daring Timlo.net diantaranya:

$$
\text { " me (N)-gelar } \rightarrow \text { menggelar" }
$$

Afiks me-/-kan, me(N)-, dan -kan memiliki kecenderungan membentuk kelas verba (Setiawan, 2016). Sejalan dengan pernyatan tersebut Chaer (2008:106) dalam (Due, 2015) menyatakan bahwa afiksasi adalah salah satu proses dalam pembentukan kata turunan baik berkategori verba, berkategori nomina maupun yang berkategori adjektiva. Penggunaan me (N) - memiliki fungsi yaitu pembentuk verba aktif. Menggelar mempunyai makna melakukan aktivitas. Jadi, awalan me (N)- menjadi menge- bila bergabung dengan kata dasar bersuku satu.

$$
\text { " ber-kerja } \rightarrow \text { bekerja " }
$$

Prefiks atau awalan be(R)-

be(R)- $\rightarrow$ alomorf be-, ber-, bel- 
Awalan ber- bervariasi menjadi be- jika dirangkaikan dengan kata yang suku pertamanya berbunyi "er" jadi berkerja menjadi bekerja

Kedua, Kesalahan singkatan. Dalam penulisan singkatan di berita, banyak pembaca yang sulit mengerti arti singkatan tersebut seperti contoh berikut ini :

"Kegiatan ini bertujuan meningkatkan kualitas SDM "

Kalimat di belakang SDM dapat diberi dengan tanda kurung arti dari singkatan tersebut, yakni menjadi (Sumber Daya Manusia). Sehingga kalimat yang benar yaitu "Kegiatan ini bertujuan meningkatkan kualitas SDM (Sumber Daya Manusia)".

"Seluruh korban langsung dievakuasi ke RS Bhayangkara Polda Jatim "

Kalimat di belakang Polda Jatim dapat diberi dengan tanda kurung arti singkatan tersebut, yakni menjadi (Polisi Daerah Jawa Timur).

Dalam penulisan judul tidak boleh disingkat, dikarenakan kurang efektif. Berikut contoh penulisan judul yang benar :

"Pegawai Setda Gelar Gathering"

Kalimat judul di atas kurang efektif karena setda tidak boleh disingkat, jadi judul yang baik dan benar yaitu "pegawai Sekretaris Daerah Gelar Gathering".

Ketiga, Kesalahan penulisan kata asing. Dalam menulis kata asing seharusnya dicetak miring seperti contoh berikut ini :

"Pegawai Setda Gelar Gathering "

Kalimat tersebut, dalam penulisan kata Gathering harusnya miring karena kata Gathering merupakan kata asing, sehingga penulisan kata Gathering harus miring. Jadi kalimat yang benar yaitu "Pegawai Setda Gelar Gathering".

Keempat, Kesalahan penulisan Kata baku. Banyak penulis berita yang salah saat menulis kata baku seperti contoh berikut ini :

“Tak Ada Hujan Tak Ada Angin, Suzuki Ignis Nyungsep ke Selokan "

Dalam penulisan kata "Nyungsep" tidak baku. Kata Nyungsep bisa diganti dengan masuk atau terjun. Jadi kalimat yang benar yaitu, "Tak Ada Hujan Tak Ada Angin, Suzuki Ignis Terjun ke Selokan".

Kelima, Kesalahan penulisan kata gabung. Kata "antar" penggunaannya tidak tepat. Sehingga banyak penulisan kata antar yang salah seperti contoh berikut ini :

" kerja sama antar pegawai "

Dalam penulisan kata antar pegawai tidak benar karena kata antar pegawai harus digabung. Kata antar merupakan unsur terikat. Jadi kata antar pegawai harus digabung dan penulisan yang benar yaitu "kerja sama antarpegawai".

“ saling membantu antar lini dalam pekerjaan "

Dalam penulisan kata antarlini tidak benar karena kata antarlini harus digabung. Kata antar merupakan unsur terikat. Jadi kata antarlini harus digabung dan penulisan yang benar yaitu, "saling membantu antarlini dalam pekerjaan".

Keenam, Kesalahan penulisan kata reduplikasi. Reduplikasi atau bentuk ulang ialah proses morfologis dengan melalui peristiwa pengulangan bentuk yang menghasilkan bentuk ulang (Setyowati, 2012).

"Tak ada korban jiwa, hanya hanya luka ringan "

Kalimat tersebut tidak efektif karena reduplikasi tidak tepat penggunaannya. Kalimat yang benar menjadi "Tak ada korban jiwa, hanya luka ringan" 


\section{KESIMPULAN}

Hasil penelitian menunjukkan kesalahan berbahasa tataran morfologi pada berita daring Timlo.net meliputi : afiksasi, singkatan, penggunaan kata asing, penggunaan kata baku, penggunaan kata gabung, dan reduplikasi. Dari hasil penelitian dapat disimpulkan bahwa berita daring kedepannya tidak boleh sembarang mempublikasikan berita. Media berita daring harus jeli mengoreksi penulisan bahasanya kembali dengan mengutamakan kaidah bahasa Indonesia. Media harus menjadi teladan dan pelopor dalam penggunaan bahasa Indonesia yang baik dan benar.

\section{REFERENSI}

Ambarita, E., \& Sibarani, R. (2017). Daftar Morfem dalam Sistem Morfologi Generatif Bahasa Batak Toba.

Ariyani, F. (2014). Distribusi Verba Berprefiks $\{\mathrm{N}-\}$ pada Bahasa Lampung dalam Kitab Kuntara Raja Niti dan Buku Ajar: Kajian Morfologi. Ranah: Jurnal Kajian Bahasa, 3(2), 124-134.

Astuti, Y. W., \& Mustadi, A. (2014). Pengaruh penggunaan media film animasi terhadap keterampilan menulis karangan narasi siswa kelas V SD. Jurnal Prima Edukasia, 2(2), 250-262.

Due, A. (2015). Reduplikasi Bahasa Kambowa. Jurnal Humanika, 3(16).

Fatimah, F. N., Purnamasari, D., Pratiwi, D., \& Firmansyah, D. (2018). Analisis Kesalahan Berbahasa pada Tuturan Pembawa Acara dan Bintang Tamu dalam Talk Show Hitam Putih yang Berjudul "Fenomena Kanjeng Dimas". Parole (Jurnal Pendidikan Bahasa dan Sastra Indonesia), 1(5), 775-786.

Inderasari, E., \& Agustina, T. (2017). Pembelajaran bahasa Indonesia pada mahasiswa asing dalam program BIPA IAIN Surakarta. Jurnal Pendidikan Bahasa dan Sastra Indonesia, 6(2), 6-15.

Marsudi, M., \& Zahrok, S. (2015). Kesetiaan Berbahasa Indonesia Dipertanyakan di Era Globalisasi. Jurnal Sosial Humaniora, 8(1), 95-105.

Nurwicaksono, B. D., \& Amelia, D. (2018). Analisis Kesalahan Berbahasa Indonesia Pada Teks Ilmiah Mahasiswa. Aksis: Jurnal Pendidikan Bahasa dan Sastra Indonesia, 2(2), 138-153.

Priyono, Y. (2012). Analisis kesalahan berbahasa bidang morfologi pada mading di Universitas Muhammadiyah Surakarta (Doctoral dissertation, Universitas Muhammadiyah Surakarta).

Rondiyah, A. A., Wardani, N. E., \& Saddhono, K. (2017). Pembelajaran Sastra Melalui Bahasa Dan Budaya Untuk Meningkatkan Pendidikan Karakter Kebangsaan Di Era Mea (Masayarakat Ekonomi Asean). In Proceedings Education and Language International Conference (Vol. 1, No. 1).

Saddhono, K. (2006). Bahasa Etnik Madura di Lingkungan Sosial: Kajian Sosiolinguistik di Kota Surakarta.

Saddhono, K. (2007). Bahasa Etnik Pendatang di Ranah Pendidikan Kajian Sosiolinguistik Masyarakat Madura di Kota Surakarta. Jurnal Pendidikan dan Kebudayaan, 13(66), 469487. 
Saddhono, K. (2012). Kajian Sosiolingustik Pemakaian Bahasa Mahasiswa Asing Dalam Pembelajaran Bahasa Indonesia Untuk Penutur Asing (BIPA) di Universitas Sebelas Maret. Kajian Linguistik dan Sastra, 24(2), 176-186. https://doi.org/10.23917/kls.v24i2.96

Saddhono, K. (2015). Integrating Culture in Indonesian Language Learning for Foreign Speakers at Indonesian Universities. Journal of Language and Literature, 6(2), 349-353.

Sardila, V. (2016). Strategi Pengembangan Linguistik Terapan Melalui Kemampuan Menulis Biografi dan Autobiografi: Sebuah Upaya Membangun Keterampilan Menulis Kreatif Mahasiswa. An-Nida' , 40(2), 110-117.

Setiawan, I. (2016). Afiks me-/-kan dan me (n)-/-kan Pada Teks Debat Calon Presiden Republik Indonesia Periode Tahun 2014-2019: Tinjauan Morfologi Derivasi Dan Infleksi. Tutur: Cakrawala Kajian Bahasa-Bahasa Nusantara, 2(2), 27-40.

Setyowati, L. (2012). Analisis Morfologi Pada Karangan Siswa Kelas VIII D SMP Muhammadiyah 5 Surakarta (Doctoral dissertation, Universitas Muhammadiyah Surakarta).

Sutrisna, D. (2017). Analisis Kesalahan Morfologi Bahasa Indonesia dalam Surat Kabar Radar Majalengka Edisi 16 dan 25 April 2016. Diglosia: Jurnal Pendidikan, Kebahasaan, dan Kesusastraan Indonesia, 1(1).

Utami, S. R. (2017). Pembelajaran Aspek Tata Bahasa dalam Buku Pelajaran Bahasa Indonesia. Aksis: Jurnal Pendidikan Bahasa dan Sastra Indonesia, 1(2). 189- 203. doi: doi.org/10.21009/AKSIS.010203

Widwiarti, Y. (2014). Analisis Kesalahan Berbahasa dalam Karangan Bahasa Indonesia Siswa Kelas IX SMK Negeri Rembang Kabupaten Pasuruan Tahun 2013/2014. dalam Jurnal NOSI, 2(3). 